\title{
In vitro evaluation of the behaviour of human polymorphonuclear neutrophils in direct contact with chitosan-based membranes
}

\author{
T.C. Santos ${ }^{a, b}$, A.P. Marques ${ }^{a, b}$, S.S. Silva ${ }^{a, b}$, J.M. Oliveira ${ }^{a, b}$, \\ J.F. Mano ${ }^{\mathrm{a}, \mathrm{b}}$, A.G. Castro ${ }^{\mathrm{c}}$, R.L. Reis ${ }^{\mathrm{a}, \mathrm{b}, *}$ \\ a 3B's Research Group - Biomaterials, Biodegradables and Biomimetics, Department of Polymer Engineering, \\ Campus de Gualtar, 4710-057 Braga, Portugal \\ ${ }^{\mathrm{b}}$ IBB - Institute for Biotechnology and Bioengineering, Braga, Portugal \\ ${ }^{\mathrm{c}}$ Life and Health Sciences Research Institute (ICVS), School of Health Sciences, \\ University of Minho, Campus de Gualtar, 4710-057 Braga, Portugal
}

Received 2 January 2007; received in revised form 22 June 2007; accepted 6 July 2007

\begin{abstract}
Several novel biodegradable materials have been proposed for wound healing applications in the past few years. Taking into consideration the biocompatibility of chitosan-based biomaterials, and that they promote adequate cell adhesion, this work aims at investigating the effect of chitosanbased membranes, over the activation of human polymorphonuclear neutrophils (PMNs). The recruitment and activation of polymorphonuclear neutrophils (PMNs) reflects a primary reaction to foreign bodies. Activation of neutrophils results in the production of reactive oxygen species (ROS) such as $\mathrm{O}_{2}^{-}$and $\mathrm{HO}^{-}$and the release of hydrolytic enzymes which are determinant factors in the inflammatory process, playing an essential role in the healing mechanisms.

PMNs isolated from human peripheral blood of healthy volunteers were cultured in the presence of chitosan or chitosan/soy newly developed membranes. The effect of the biomaterials on the activation of PMNs was assessed by the quantification of lysozyme and ROS.

The results showed that PMNs, in the presence of the chitosan-based membranes secrete similar lysozyme amounts, as compared to controls (PMNs without materials) and also showed that the materials do not stimulate the production of either $\mathrm{O}_{2}^{-}$or $\mathrm{HO}^{-}$. $\mathrm{Moreover} \mathrm{PMNs}$ incubated with the biomaterials when stimulated with phorbol 12-myristate 13-acetate (PMA) or formyl-methionyl-leucyl-phenylalanine (fMLP) showed a chemiluminescence profile with a slightly lower intensity, to that observed for positive controls (cells without materials and stimulated with PMA), which reflects the maintenance of their stimulation capacity.

Our data suggests that the new biomaterials studied herein do not elicit activation of PMNs, as assessed by the low lysozyme activity and by the minor detection of ROS by chemiluminescence. These findings reinforce previous statements supporting the suitability of chitosan-based materials for wound healing applications.
\end{abstract}

(C) 2007 Published by Elsevier B.V.

Keywords: Chitosan; Soy; Lysozyme; Reactive oxygen species; Neutrophils; Wound healing

\section{Introduction}

In the past few years a huge effort has been made to create the ideal wound dressing and skin substitutes to respond to the increasing needs of mankind. Several research groups suggested that chitosan is a promising material for regenera-

\footnotetext{
* Corresponding author at: 3B's Research Group - Biomaterials, Biodegradables and Biomimetics, University of Minho, Campus de Gualtar, 4710-057 Braga, Portugal. Tel.: +351 253604781; fax: +351 253604498 .

E-mail address: ruigreis@dep.uminho.pt (R.L. Reis).
}

tive medicine (Shi et al., 2006; Marreco et al., 2004; Azad et al., 2004; Khor and Lim, 2003). Chitosan-based membranes were shown to promote the proliferation of human skin fibroblasts and keratinocytes in vitro (Azad et al., 2004) and the application of a chitosan-based hydrogel in mice wounds had proved to accelerate wounding (Ishihara et al., 2001). Furthermore it was demonstrated that wounds in human skin heal better if covered with chitosan-based membranes (Howling et al., 2001; Wedmore et al., 2006), beyond its proven antimicrobial properties (Burkatovskaya et al., 2006; Singla and Chawla, 2001). 
After implantation of a medical device, the tissue will inevitably be traumatized by the implantation procedure (Mikos et al., 1998; Hunt, 2001; Stevens et al., 2002; Williams, 2001) triggering an inflammatory response. This response to trauma and to the implantation of biomaterials is associated to the secretion of a variety of mediators (Hunt, 2001; Mikos et al., 1998; Stevens et al., 2002; Williams, 2001). Their action results in the recruitment of certain populations of cells that, if not properly regulated, can cause tissue damage and ultimately lead to the rejection of the implant (Williams, 2001). The concomitant increased vascular permeability in the inflammatory response allows the influx of circulating inflammatory cells to the implantation site, in a first phase, polymorphonuclear neutrophils (PMNs). Within $24 \mathrm{~h}$, macrophages also begin to migrate to the site of injury and 2 or 3 days following the beginning of the inflammatory process, lymphocytes begin to enter the damaged area. Together with this influx, other inflammatory cells, such as mast cells and eosinophils will orchestrate the ongoing of the inflammatory response to the implanted device.

It is well known that PMNs are crucial early in the development of an inflammatory response (Marques et al., 2005; Chander et al., 1989; Stevens et al., 2002). Neutrophils also have the capacity to dictate the progression of the host immune system reaction by their capacity to produce cytokines, such as IL-12 and IL-10 among others (Martin and Leibovich, 2005; Marques et al., 2004; Stevens et al., 2002). PMNs have a high capacity to act as phagocytes of foreign bodies, nevertheless, the great majority of biomaterials comprises a range of dimensions incompatible with phagocytosis, leading PMNs to "frustrated phagocytosis" (Liu et al., 1997) resulting in the release of hydrolytic enzymes (Mutasa, 1989; Rice et al., 1986), known as an oxygen-independent mechanism (Segal, 2005). Lysozyme, present in both primary and secondary granules of PMNs, is one of the most important enzymes released during the inflammatory response (Mutasa, 1989; Rice et al., 1986). The importance of its role in the foreign body reaction to biodegradable biomaterials is further supported by its capacity to degrade polymers such as chitosan (Etienne et al., 2005).

Another defence approach that is potentially deleterious for the implanted device occurs simultaneously to degranulation and is commonly designated as respiratory burst. This PMNs oxygen-dependent mechanism of defence, involve the consumption of oxygen $\left(\mathrm{O}_{2}\right)$ by the activation of the nicotinamide adenine dinucleotide phosphate (NADPH) oxidase system, leading to the production of oxygen radicals and their reaction products-reactive oxygen species (ROS) which are know to induce tissue destruction (Segal, 2005).

The aim of this study was to gain further knowledge on the biological reactions to chitosan and chitosan/soy based membranes meant for wound healing applications. Reis and his group have shown previously that (Silva et al., 2005), chitosan-based membranes were non cytotoxic and support mouse fibroblast cell adhesion and spreading. These new systems combine the blending of natural polymers, such as chitosan and soy (Silva et al., 2004; Silva et al., 2005), in order to develop hybrid materials for tissue engineering and regenerative medicine. In fact, chitosan-based systems have been proposed by the same group for several different applications within the tissue and regenerative field (Pedro et al., 2005; Tuzlakoglu et al., 2004; Silva et al., 2004). Therefore the present study intended to focus on the effect of the presence of the newly developed chitosan-based membranes over the in vitro response of PMNs isolated from human blood. The considered newly developed biomaterials are the chitosan/soy blends, thus the membranes of chitosan blended with soy in two forms, one comprehending simply the blend of chitosan with soy (Cht/Soy), and the other which is the same blend but cross-linked with TEOS (Cht/Soy/TEOS). PMNs degranulation was addressed by quantification of the granular hydrolytic enzyme lysozyme while the respiratory burst mechanisms were followed by a chemiluminescence assay (Robinson, 1998; Li et al., 1998) knowing that PMNs can be stimulated in vitro with phorbol 12-myristate 13-acetate (PMA) (Azadniv et al., 2001; Marques et al., 2003) or formyl-methionyl-leucyl-phenylalanine (fMLP) (Robinson, 1998; Lee et al., 2005; Marques et al., 2003).

\section{Materials and methods}

\subsection{Materials tested}

Reagent grade chitosan (CHT, Sigma, USA) with a deacetylation degree of $85 \%$ and viscosimetric molecular weight of about $700 \mathrm{KDa}$, Soy protein isolate (Loders Crocklaan, The Netherlands) and tetraethyl orthosilicate (TEOS, Aldrich, USA) were used on the preparation of the different membranes. All other reagents were also analytical grade and used as received.

Chitosan, chitosan/soy protein blended membranes (Cht) were prepared by means of solvent casting, as previously reported by the group of Reis (Silva et al., 2005). By its turn, the chitosan-soy protein hybrid membranes (Cht/Soy) were produced by means of a combination of a sol-gel method and solvent casting (Silva et al., 2006). Firstly, a 4 wt\% chitosan solution was prepared by dissolving chitosan in $0.2 \mathrm{M}$ acetic acid solution. Secondly, a $1 \mathrm{wt} \%$ soy suspension (water/glycerol $(10 \% \mathrm{w} / \mathrm{v}))$ was also prepared and the $\mathrm{pH}$ adjusted to $8.0 \pm 0.3$ with $1 \mathrm{M}$ sodium hydroxide solution. Then, the dispersion was heated in a water bath at $50{ }^{\circ} \mathrm{C}$ for $30 \mathrm{~min}$. The blend was prepared by means of mixing the solutions (75/25 wt $\%$ chitosan-soy protein) under constant agitation for the period of $1 \mathrm{~h}$. The cross-linking agent TEOS and $0.5 \mathrm{M}$ chloridric acid $(\mathrm{HCl})$ solution in the molar ratio (TEOS: $\mathrm{HCl})$ of 1:0.1 wt\% were added to the blend to Cht:TEOS ratio of 10:0.1 wt\%, under constant stirring for $24 \mathrm{~h}$. Following the solvent casting methodology, the blended solutions was poured into a Petri dish and allowed to dry at room temperature for several days, followed by neutralisation using a $0.1 \mathrm{M}$ sodium hydroxide solution, as described elsewhere (Silva et al., 2006).

The referred to chitosan-based membranes were considered for the studies: chitosan membranes (Cht), membranes of chitosan blended with soy in two forms, one comprehending simply the blend of chitosan with soy (Cht/Soy), and the other which is the same blend but cross-linked with TEOS, i.e. hybrid membranes (Cht/Soy/TEOS). Three samples of each different membrane were tested and four repetitions of each test were performed. The samples were sterilized by ethylene oxide (EtO) 
in conditions that have been described previously (Reis et al., 1997).

For the quantification of lysozyme the considered incubation periods were of $30 \mathrm{~min}, 1 \mathrm{~h}$ and 2 . For the reactive oxygen species detection a kinetic study were performed from the time point zero to a maximum of $2 \mathrm{~h}$, without previous incubation.

\subsection{Cells}

Human polymorphonuclear neutrophils (PMN) were isolated from heparinized fresh peripheral blood. Each $10 \mathrm{~mL}$ of heparinized blood was placed in $10 \mathrm{~mL}$ of Dextran (Sigma, St. Louis, USA) (6\% solution in PBS without $\mathrm{Ca}$ and $\mathrm{Mg}-$ Sigma, St. Louis, USA). After $20 \mathrm{~min}$, about $6 \mathrm{~mL}$ of the top layer was removed with a glass pipette and carefully added to $4 \mathrm{~mL}$ of Histopaque 1077 (Sigma, St. Louis, USA). After a 25 min centrifugation at $21^{\circ} \mathrm{C}$ and $2400 \mathrm{rpm}$, the cloudy layer was firstly removed and then the others, keeping the bottom red pellet to resuspend it with $5 \mathrm{~mL}$ of PBS without $\mathrm{Ca}^{2+}$ and $\mathrm{Mg}^{2+}$. The tube was filled up with PBS (about $12 \mathrm{~mL}$ ). A centrifugation for $25 \mathrm{~min}$ at $21^{\circ} \mathrm{C}$ and $2400 \mathrm{rpm}$ was performed and the supernatant was removed. One millilitre of distilled water was added, triturated three times with the glass pipette and shacked gently for $35 \mathrm{~s}$, in order to lyse erythrocytes. The tube was quickly filled up with PBS without $\mathrm{Ca}$ and $\mathrm{Mg}$. The cells were washed by centrifugation, for $25 \mathrm{~min}$ at $21^{\circ} \mathrm{C}$ and $2400 \mathrm{rpm}$, the supernatant was removed as well as the top of the red pellet, very carefully, without touching the white pellet in the bottom. The tube was filled up again with PBS without $\mathrm{Ca}$ and $\mathrm{Mg}$ and centrifuged for $25 \mathrm{~min}$ at $21^{\circ} \mathrm{C}$ and $2400 \mathrm{rpm}$. The supernatant was removed and the volume needed of PBS without $\mathrm{Ca}$ and $\mathrm{Mg}$ was added to count the number of cells after resuspension. The cell suspension was kept at $4{ }^{\circ} \mathrm{C}$ until the assays were performed, within a maximum of $2 \mathrm{~h}$.

The cell suspensions used were of $1.3 \times 10^{6}$ cells $/ \mathrm{mL}$ for the reactive oxygen species assay and $100 \mu \mathrm{L}$ of cell suspension per well, and $5 \times 10^{5}$ cells $/ \mathrm{mL}$ and $1.0 \mathrm{~mL}$ of cell suspension per well for the lysozyme assay.

\subsection{Lysozyme quantification}

A bacterial (Micrococcus lysodeikticus_-Sigma, St. Louis, USA) suspension of $1.5 \mathrm{mg} / \mathrm{mL}$ was prepared. The isolated PMN were resuspended in PBS with $\mathrm{Ca}$ and $\mathrm{Mg}$ (Sigma, St. Louis, USA) (to promote cell attachment) at a final concentration of $5 \times 10^{5}$ cells $/ \mathrm{mL}$. Each sample material ( $14 \mathrm{~mm}$ diameter) was incubated with $1 \mathrm{~mL}$ of the previous cell suspension (in PBS with $\mathrm{Ca}$ and $\mathrm{Mg}$ ), for the three pre-determined time periods of reaction ( $30 \mathrm{~min}, 1$ and $2 \mathrm{~h}$ ), at $37^{\circ} \mathrm{C}$ and in a humid atmosphere with $5 \% \mathrm{CO}_{2}$ and non-adherent 24-well plates. Three wells with the cell suspension alone were incubated for the same periods of reaction, acting as negative controls.

After each incubation period, $0.5 \mathrm{~mL}$ of the supernatant were transferred to new wells and $0.5 \mathrm{~mL} /$ well of the bacterial suspension previously prepared was added. The new wells with the lysozyme of the PMN (released when in contact with the materials) and the bacterial suspension were incubated for $30 \mathrm{~min}$, at $37^{\circ} \mathrm{C}$ and in a humid atmosphere with $5 \% \mathrm{CO}_{2}$. After incubation, the optical density (OD) was recorded at $541 \mathrm{~nm}$. The concentration of the viable cells in the bacterial suspension is quantified by the changes in the turbidity of the bacterial suspension. The cell wall of the bacteria acts as a substrate for lysozyme, leading to the cleavage and consequent lysis of the cell. The intact bacterial suspension is characteristically opaque, but after incubation with a lysozyme solution, the turbidity decreases with the increasing bacterial lysis (Salton, 1957). After the absorbance reading of the samples, controls and the standards, the lysozyme secreted form the PMN after the contact with the materials, was quantified normalizing the OD values to a calibration curve of known concentrations of lysozyme.

\subsection{Reactive oxygen species quantification}

The isolated PMN were resuspended in PBS with $\mathrm{Ca}$ and $\mathrm{Mg}$ at a final concentration of $1.3 \times 10^{6}$ cells $/ \mathrm{mL}$. A mixture of cells $(100 \mu \mathrm{L})$, with or without cell stimulants (phorbol 12-myristate 13-acetate (PMA) (Sigma, St. Louis, USA), $8 \mu \mathrm{g} / \mathrm{mL}$ in PBS or formyl-methionyl-leucyl-phenylalanine (fMLP) (Fluka, St. Louis, USA), $10 \mu \mathrm{g} / \mathrm{mL}$ in PBS $(100 \mu \mathrm{L}$ each), with luminol (Sigma, St. Louis, USA) 1.5 Mm in PBS and lucigenin (Sigma, St. Louis, USA), $5.4 \times 10^{-5} \mathrm{M}$ in PBS (Sigma, St. Louis, USA) $(100 \mu \mathrm{L}$ each), and with or without materials were made in the wells of a white opaque 96-well plate. In this step, the cells, the reagents and the plate were kept on ice. The chemiluminescence was read in a microplate reader (Sinergy HT, BioTech). The results were obtained in terms of number of counts per time period.

\section{Results and discussion}

\subsection{Lysozyme secretion}

Wound healing is a very complex process involving a number of cells, mediators and molecules that, if not properly regulated, may lead to severe damage of the surrounding tissues. If the wounded tissue is the skin, the inflammatory response is accompanied by re-epithelialization, formation of granulation tissue and contraction of connective tissue (Martin and Leibovich, 2005). Neutrophils play an important role in the development of the inflammatory response and, in the particular situation of a skin wound they can dictate the progression of the healing. PMNs can be activated by multiple mechanisms (McPhail et al., 1981) resulting in an increased phagocytic activity as well as in the release of hydrolytic enzymes, such as lysozyme, from their cytoplasmic granules (Rice et al., 1986; Borregaard and Cowland, 1997). When activated neutrophils phagocytose necrotic tissue debris (Stevens et al., 2002) but also try to phagocytose the damaging material which is promoted by a coating of immunoglobulins and proteins of the complement system (Stevens et al., 2002). The attempt to eliminate the harmful agent is endorsed by the lytic enzymes, including lysozyme that can be released during the process of frustrated phagocytosis, when the material is too large to be internalized, or in association with the respiratory burst (Hunt, 2001). Nevertheless, the lytic activity 


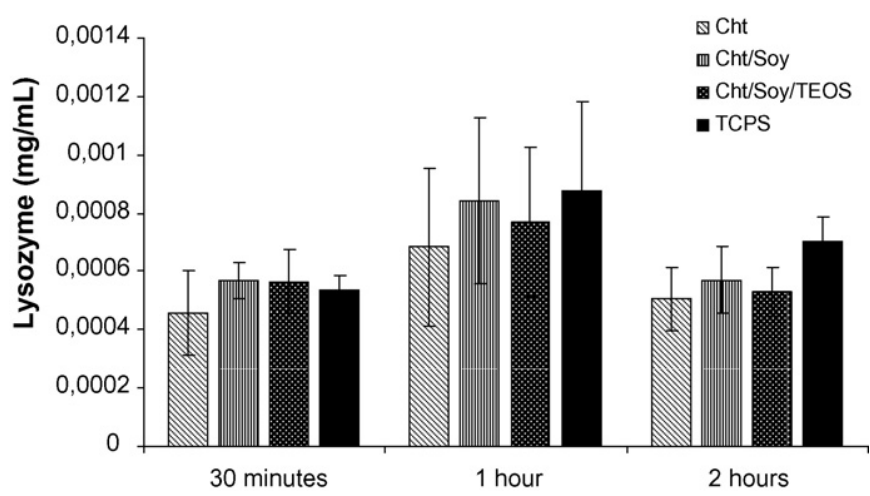

Fig. 1. Amount of lysozyme secreted by the PMN after 30, 60 and $120 \mathrm{~min}$ in direct contact with Chitosan-based membranes. No statistical difference was detected when comparing the lysozyme secretion profile between the Chitosanbased membranes and the tissue culture polystyrene (TCPS).

of neutrophils is limited by their inability to regenerate lysosomal enzymes and, after the "respiratory burst", neutrophils degenerate (Stevens et al., 2002; Segal, 2005).

In the present work, the lysozyme secreted by the PMNs in direct contact with the Chitosan-based membranes was quantified by a spectrophotometric assay. The amount of lysozyme secreted by PMNs after 30 min of incubation with the chitosan (Cht), chitosan and soy (Cht/Soy) and Cht/soy cross-linked with TEOS (Cht/Soy/TEOS) membranes was similar (Fig. 1). Moreover, it was not observed a significant difference from the values obtained for the negative control, where the cells were incubated with tissue culture polystyrene (TCPS). Increasing incubation times ( 1 and $2 \mathrm{~h}$ ) revealed that the peak of lysozyme secretion occurred at $1 \mathrm{~h}$ and that after that time the amount of enzyme produced by the cells reached the values of the earlier time point. However, as the same profile was observed for all the tested conditions, it can be concluded that the amount of lysozyme secreted at each time point was comparable for the three types of chitosan-based membranes and the negative control and that there were no significant differences along the assay.

The lysozyme quantification data suggest that the membranes of Cht, Cht/soy and Cht/Soy/TEOS were able to activate the PMNs in a comparable degree as the TCPS. Therefore the developed chitosan-based membranes did not have any significant effect on PMNs degranulation.

\subsection{Chemiluminescence}

The increased metabolism of activated neutrophils is translated in the so called "respiratory burst", which results in the generation of superoxide anions $\left(\mathrm{O}_{2}^{-}\right)$, hydrogen peroxide $\left(\mathrm{H}_{2} \mathrm{O}_{2}\right)$, singlet oxygen $\left({ }^{1} \mathrm{O}_{2}\right)$ and hydroxyl radicals $\left(\mathrm{OH}^{-}\right)$ (Segal, 2005; Stevens et al., 2002; Williams, 2001). Despite the apoptotic self destruction mechanism of PMNs once they finish their functions at the wound site and their rapid recognition and clearance by macrophages (Schwartz et al., 1999), the accumulation of PMNs at injury sites is not unusual to occur. This gathering of PMNs at the site of implantation or injury, specially in the cases of chronic wounds, blitz the environment with free radicals that kill healthy host cells (Martin and Leibovich, 2005).
In fact, it is well known that the respiratory burst of neutrophils has harmful effects on themselves and on surrounding healthy tissues (Fadeel et al., 1998; Tuo et al., 1999). Therefore, it is imperative to gain further knowledge on the in vitro behaviour of PMNs in direct contact with newly developed materials to predict, as much as possible, their role in the in vivo inflammatory reaction.

The assessment of the effect of the chitosan-based membranes on PMN activation was further achieved by the quantification of the produced ROS using a chemiluminescence assay (Marques et al., 2003), in the presence and absence of cell stimulants (PMA and fMLP). This two cell stimulants were chosen due to their different mechanisms of action; PMA activates neutrophils directly at the level of Protein Kinase C (Melloni et al., 1986; McPhail et al., 1981) while fMLP activates NADPHoxidase (McPhail et al., 1981) thus allowing to conclude about the signalling pathways activated by the contact with the materials studied.

As previously reported (Silva et al., submitted for publication), the developed chitosan-based membranes used in this work showed the following features: (i) higher surface roughness $(7.0 \mu \mathrm{m})$ of the $\mathrm{Cht} / \mathrm{Soy} / \mathrm{TEOS}$ membranes in comparison to Cht and Cht/Soy membranes (4.6 and $2.5 \mu \mathrm{m}$, respectively); (ii) contact angles values between 80 and $117^{\circ}$ and thus an hydrophobic nature, and (iii) increasing of surface energy of the blended membranes in comparison to Cht membranes. All resulting changes are related to both incorporation of soy protein and inorganic phase (TEOS). More details about the characterization of the membranes can be found elsewhere (Silva et al., submitted for publication).

The kinetics of PMN activation induced by PMA and IMLP was determined under the same conditions as the assays performed in the presence of the materials in study and represents the maximum capacity of the cells to be activated under the defined conditions (Fig. 2). Superoxide anion $\left(\mathrm{O}_{2}{ }^{-}\right)$generation was detected by the oxidation of lucigenin while the generation of the hydroxyl anion $\left(\mathrm{HO}^{-}\right)$was detected from the oxidation of luminol. In the tested conditions, PMA was able to stimulate human neutrophils for the production of either $\mathrm{O}_{2}{ }^{-}$or $\mathrm{HO}^{-}$. The stimulation with PMA induced the cells to start to produce $\mathrm{HO}^{-}$after $10 \mathrm{~min}$ of incubation. This stimulation was prolonged for approximately $1 \mathrm{~h} 12 \mathrm{~min}$, reaching its peak around $25 \mathrm{~min}$ after the beginning of the stimulation with PMA.

The production of $\mathrm{O}_{2}{ }^{-}$, represents a later and prolonged defence mechanism compared to the production of $\mathrm{HO}^{-}$, once it started $15 \mathrm{~min}$. after the incubation with PMA and reached a maximum value approximately $1 \mathrm{~h}$ after. The stimulation with fMLP induced the PMNs to produce either $\mathrm{O}_{2}^{-}$or $\mathrm{HO}^{-}$at similar periods of time which started around $15 \mathrm{~min}$, lasted for $1 \mathrm{~h} 20 \mathrm{~min}$ and showed a maximum stimulation after $30 \mathrm{~min}$ of the beginning of stimulation. Nevertheless, the $\mathrm{O}_{2}{ }^{-}$production was lower than the production of $\mathrm{HO}^{-}$and the amount of these ROS was much lower in the fMLP stimulation compared to the stimulation with PMA.

The chemiluminescence results show that the chitosanbased membranes did not stimulate $\mathrm{PMNs}$ to produce $\mathrm{HO}^{-}$ (Figs. 3A, 4A and 5A) and represent a weak stimulus for the 


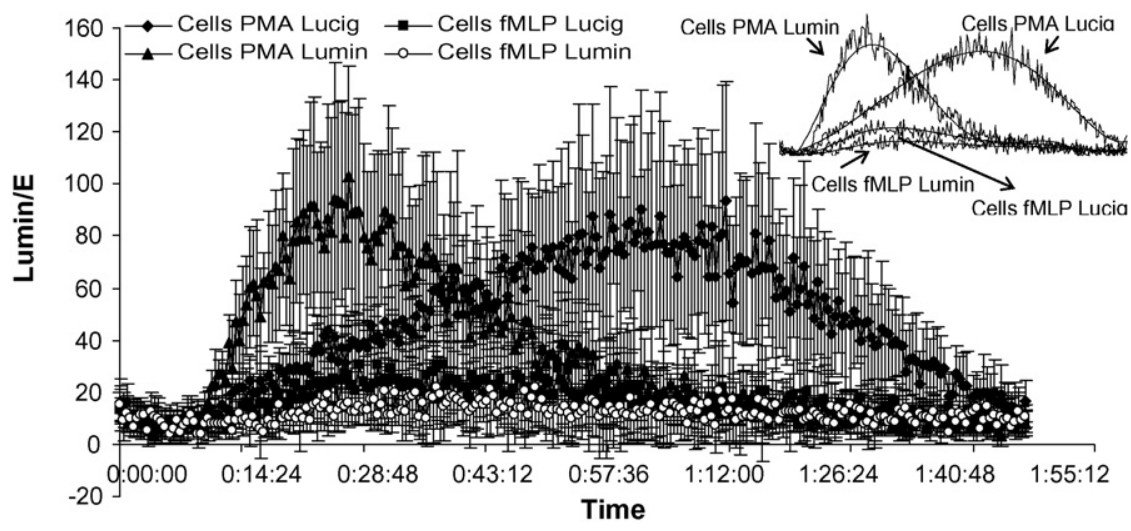

Fig. 2. PMA and fMLP-stimulated chemiluminescence profiles for polymorphonuclear neutrophils incubated for 107 min at $37^{\circ} \mathrm{C}$. Superoxide anion generation was detected by the oxidation of lucigenin while the generation of the hydroxyl anion was detected after the oxidation of luminol. In the tested conditions, PMA was able to stimulate human neutrophils for the production of either $\mathrm{O}_{2}^{-}$or $\mathrm{HO}^{-}$, but fMLP was not able to stimulate neutrophils to produce neither $\mathrm{O}_{2}{ }^{-}$nor $\mathrm{HO}^{-}$. The figure shows representative data of five separate experiments. Schematic representation of graph.

production of $\mathrm{O}_{2}^{-}$(Figs. 3B, 4B and 5B). In fact, the luminol oxidation signals presented outlines comparable to the observed for the negative controls where the cells were incubated with PBS. Nevertheless, since PMNs were able to produce $\mathrm{HO}^{-}$ or $\mathrm{O}_{2}{ }^{-}$when stimulated with PMA or fMLP in direct contact with the chitosan-based membranes, their activation capacity was retained. Additionally, the majority of the kinetic profiles of the response of PMNs to the cell stimulants in the pres- ence of the chitosan-based membranes were different from the controls. The intensity of the luminescence peak related to the production of $\mathrm{HO}^{-}$and $\mathrm{O}_{2}{ }^{-}$by cells stimulated with PMA and in direct contact with the chitosan-membranes was lower than in the control conditions (PMNs only in the presence of the stimulants-Fig. 2) and shifted in time. This means that the PMA-stimulated $\mathrm{HO}^{-}$and $\mathrm{O}_{2}{ }^{-}$production was slightly diminished and delayed in the presence of the chitosan-based
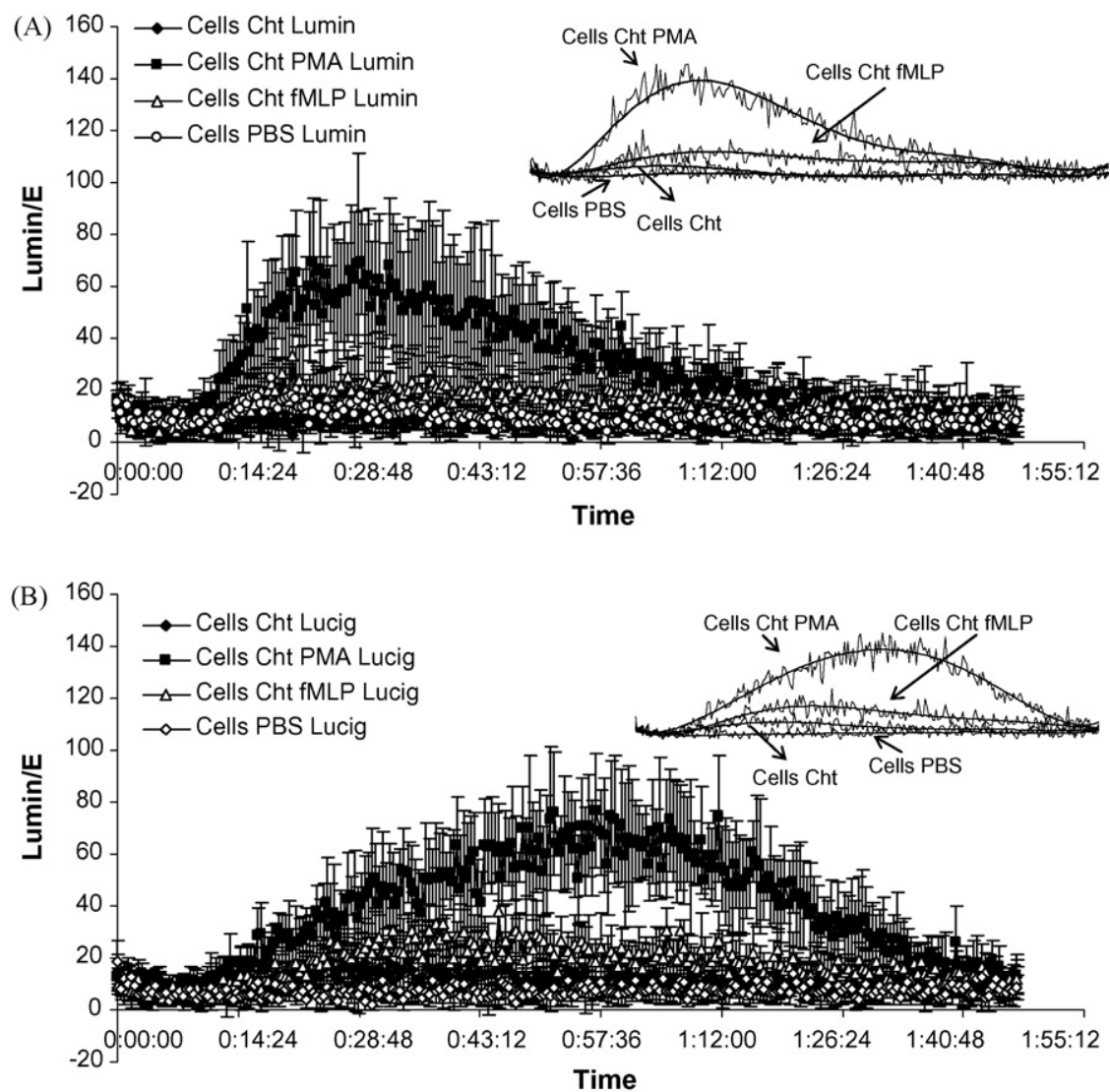

Fig. 3. Influence of chitosan membranes on the production of $\mathrm{HO}^{-}$(A) and $\mathrm{O}_{2}^{-}$(B) by polymorphonuclear neutrophils with and without PMA and fMLP stimulation. In the presence of the chitosan membranes, unstimulated PMNs and fMLP-stimulated cells did not have the ability to produce neither $\mathrm{O}_{2}{ }^{-}$nor $\mathrm{HO}^{-}$. Contrarily, PMA-stimulated PMNs in contact with the chitosan membranes produced either $\mathrm{O}_{2}{ }^{-}$or $\mathrm{HO}^{-}$. Schematic representation of graph. 

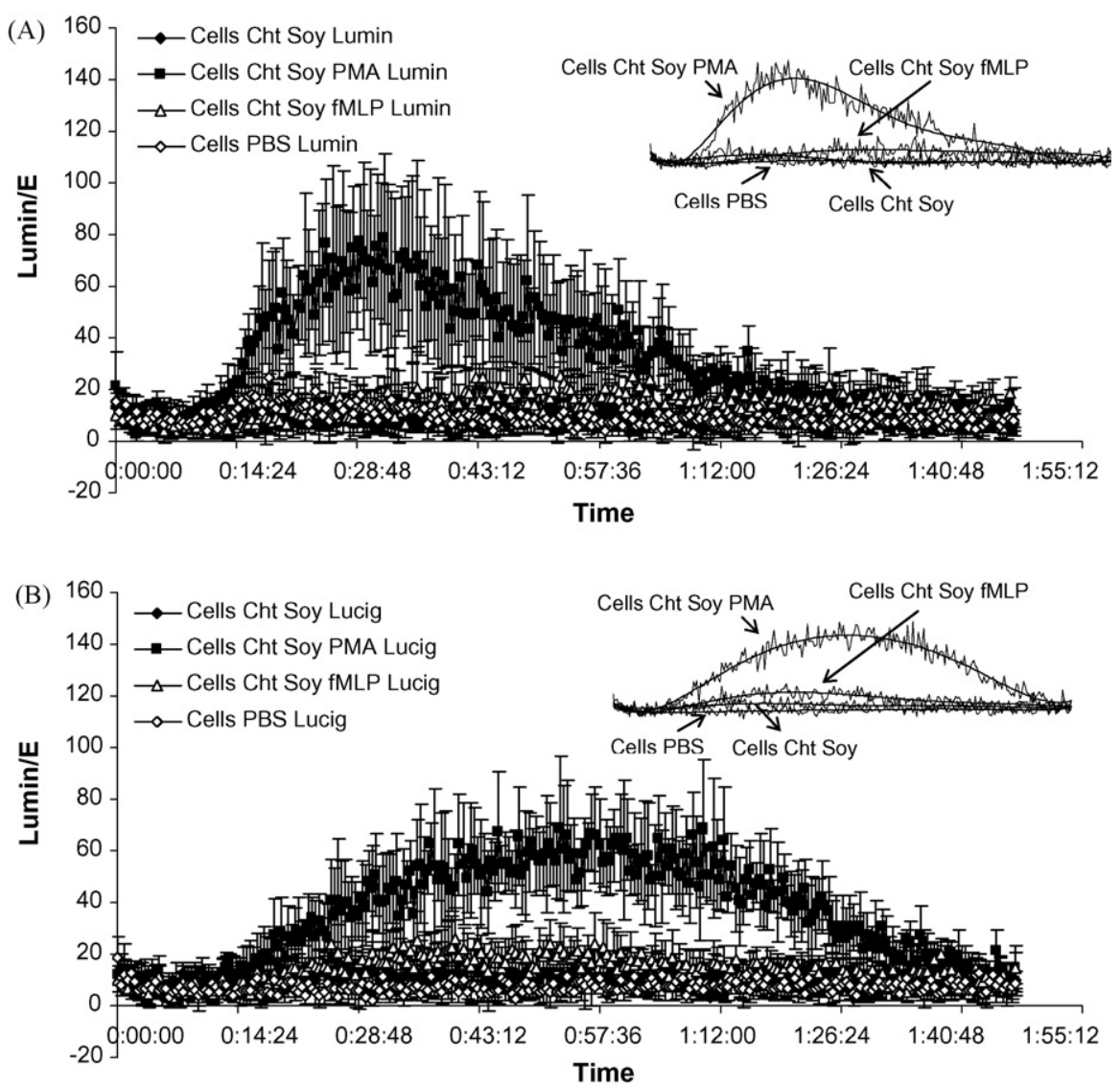

Fig. 4. Influence of chitosan/soy membranes on the production of $\mathrm{HO}^{-}$(A) and $\mathrm{O}_{2}{ }^{-}$(B) by polymorphonuclear neutrophils with and without PMA and fMLP stimulation. In the presence of the chitosan/soy membranes, unstimulated PMNs and fMLP-stimulated cells did not have the ability to produce neither $\mathrm{O}_{2}{ }^{-}$nor $\mathrm{HO}^{-}$. Contrarily, PMA-stimulated PMNs in contact with the chitosan membranes produced either $\mathrm{O}_{2}{ }^{-}$or $\mathrm{HO}^{-}$. Schematic representation of graph.

membranes. An interesting and distinct behaviour was found for the fMLP-stimulated PMNs in the presence of the developed membranes. While the fMLP-stimulated production of $\mathrm{O}_{2}{ }^{-}$was both diminished and delayed in the presence of the three tested materials (Figs. 3B, 4B and 5B), the fMLP-stimulated $\mathrm{HO}^{-}$ production was only lower and delayed in the presence of the chitosan/soy (Fig. 4A) and of the hybrid membranes (Fig. 5A). In fact fMLP-stimulated PMNs presented comparable $\mathrm{HO}^{-}$production kinetic profiles when in the control conditions (Fig. 2) and in the presence of the chitosan membranes, meaning that the chitosan membranes did not induce a lower and delayed response of PMNs (Fig. 3A).

The comparison of the chemiluminescence data from the different materials revealed that the $\mathrm{PMA}$-stimulated $\mathrm{HO}^{-}$and $\mathrm{O}_{2}{ }^{-}$ production in the presence of the chitosan/soy and hybrid membranes did not present significant differences. This similarity was also found for the fMLP-stimulated $\mathrm{HO}^{-}$production but not for the fMLP-stimulated $\mathrm{O}_{2}{ }^{-}$production in which the hybrid membranes induced a less significant effect than the chitosan/soy membranes in comparison to the control. Moreover, the chitosan membranes while exerting a more pronounced effect on stimulating PMNs over the PMA-stimulated $\mathrm{HO}^{-}$production in comparison with the control conditions and with the two other chitosan-based membranes, showed to induce comparable fMLP-stimulated $\mathrm{HO}^{-}$production to control and lower effect than the chitosan/soy and hybrid membranes also over the PMA and fMLP-stimulated $\mathrm{O}_{2}{ }^{-}$production.

It was demonstrated that the human neutrophils were successfully stimulated by PMA, with a maximum production of $\mathrm{HO}^{-}$ between 20 and $30 \mathrm{~min}$ and $\mathrm{O}_{2}{ }^{-}$and a maximum production of $\mathrm{O}_{2}{ }^{-}$between 55 and $65 \mathrm{~min}$ (Fig. 2). The stimulation for the secretion of $\mathrm{HO}^{-}$started earlier and was slightly stronger than the stimulation for the release of $\mathrm{O}_{2}{ }^{-}$, but the $\mathrm{O}_{2}{ }^{-}$-elicited oxidation of lucigenin lasted longer. The $\mathrm{HO}^{-}$and $\mathrm{O}_{2}{ }^{-}$maximum production by fMLP-stimulated neutrophils was shown to occur between 20 and $50 \mathrm{~min}$, however, the intensity of those peaks was significantly lower when compared with the production of $\mathrm{HO}^{-}$ and $\mathrm{O}_{2}{ }^{-}$by PMA-stimulated PMNs.

McPhail et al. (1981) demonstrated that modifications in the cytoplasmic membranes of neutrophils lead to cells that respond to stimuli such as PMA with normal $\mathrm{O}_{2}{ }^{-}$production, but are unable to respond normally to fMLP stimulation.

In contact with all the tested chitosan-based membranes, the PMNs were not stimulated for the release of $\mathrm{HO}^{-}$and represent a weak stimulus for the production of $\mathrm{O}_{2}{ }^{-}$. Despite the differences assessed in the surface of the chitosan-based membranes (Silva et al., 2006), the cells showed a similar behaviour in terms of activation. These observations indicate that the characteristics of those surfaces were inert for PMNs, corroborate the already assessed biocompatibility (Silva et al., 2005). Nonetheless, if the 

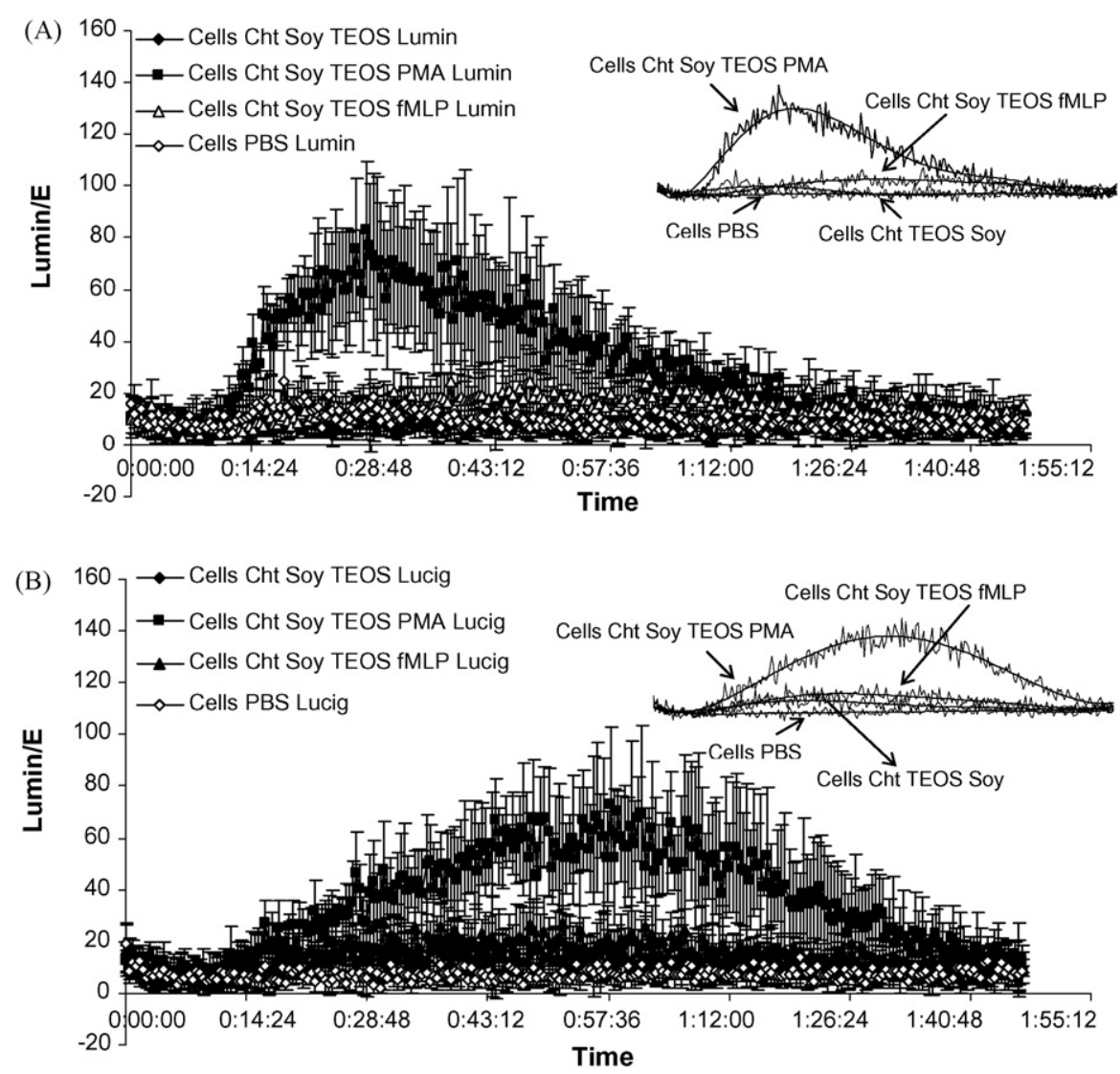

Fig. 5. Influence of hybrid membranes on the production of $\mathrm{HO}^{-}$(A) and $\mathrm{O}_{2}^{-}$(B) by polymorphonuclear neutrophils with and without PMA and fMLP stimulation. In the presence of the TEOS-crosslinked chitosan/soy membranes, unstimulated PMNs and fMLP-stimulated cells did not have the ability to produce neither $\mathrm{O}_{2}{ }^{-}$ nor $\mathrm{HO}^{-}$. Contrarily, PMA-stimulated PMNs in contact with the chitosan membranes produced either $\mathrm{O}_{2}{ }^{-}$or $\mathrm{HO}^{-}$. Schematic representation of graph.

cells were simultaneously, in direct contact with the chitosanbased membranes and stimulated with PMA or fMLP, they showed capacity to produce both $\mathrm{HO}^{-}$and $\mathrm{O}_{2}^{-}$, meaning that the contact with the chitosan-membranes did not eliminate their capacity to respond to those stimuli, although responding differently from the control conditions. This may indicate an in vivo anti-inflammatory/anti-oxidant potential of the chitosan-based membranes. In fact, the intensity of the chemiluminescence peaks resulting from PMA and fMLP stimulation in the presence of the materials is lower than in the control and was shifted in time which indicates a decrease in the amount of detected ROS and a delaying in the response of the cells to the stimuli. Thus the maximum activation capacity of the PMNs in the presence of the materials was either affected or the chitosan-based membranes have the capacity to react with the produced ROS, which can explain the lower intensity and consequently the lower amount of ROS detected.

Furthermore, the alteration in time of the signal measured might be a consequence of the cell-material interactions that occur at the surface of the different membranes. In fact, the response obtained in the presence of the chitosan membranes was different from the observed for the Cht/soy and hybrid membranes. The PMNs stimulated with PMA and in contact with chitosan membranes, showed an intensity of the chemiluminescence peak resultant from the oxidation of luminol by $\mathrm{HO}^{-}$, lower than the observed for the control and for the two other chitosan-based membranes. In contrast, chitosan membranes showed to induce comparable fMLP-stimulated $\mathrm{HO}^{-}$ production to control and higher PMA and fMLP-stimulated $\mathrm{O}_{2}{ }^{-}$production than the other materials.

The in vivo biological acceptance of an implanted biomaterial always involves inflammation and wound healing, without which the body would only tolerate the biomaterial instead of get it into a functional and long-term association (Hunt, 2001).

The chitosan/soy blended membranes were obtained by combination of chitosan and soy protein. In a previous study (Silva et al., 2005), the chemical cross-linking of these two components was performed with glutaraldehyde in order to increase their interaction reducing the immiscibility (Silva et al., 2007).

Despite the fact that the chitosan-based membranes presented a rougher surface and higher surface energy and siloxane bonds when comparing to chitosan membrane alone (Silva et al., submitted for publication), the results showed that is not possible to establish a direct correlation with the PMN's activation in direct contact with the membranes and without chemical stimulants (PMA and fMLP). Nonetheless, they still retain their capacity of activation and it is imperative to consider that the stimulation and activation of these cells is highly influenced by the type of molecules or mediators adsorbed to the surface of materials (Jackson et al., 2000; Nimeri et al., 2002) once they are implanted in vivo. PMNs that are activated mainly in response to the wound healing process subsequent to the injury produced by 
the implantation procedure, at least, are not directly activated by the chitosan/soy membranes in vitro, as it was proved by the poor activation demonstrated by the production of ROS. Even though, it is possible that, in vivo, the response elicited by the same membranes could differ. The present results show that the chitosan/soy membranes, in vitro, were not able to stimulate human PMNs neither for the release of lysozyme nor for the production of ROS found in the "respiratory burst". Nonetheless, the in vivo activation of PMNs by the implantation of any medical device for tissue engineering purposes is required at controlled levels, since their function in wound healing precedes the adaptive changes if the tissue recovers from injury and returns to normal function. The low in vitro stimulation of the PMNs induced by these chitosan/soy-based membranes seems to be a good indicator for the development of a normal wound healing process, when implanted in vivo, as well as the normal restoration of the tissue function.

\section{Acknowledgments}

This work was carried out under the scope of the European NoE EXPERTISSUES (NMP3-CT-2004-500283) and partially supported by the European STREP Project HIPPOCRATES (NMP3-CT-2003-505758).

\section{References}

Azad, A.K., Sermsintham, N., Chandrkrachang, S., Stevens, W.F., 2004. Chitosan membrane as a wound-healing dressing: characterization and clinical application. J. Biomed. Mater. Res. B Appl. Biomater. 69, 216-222.

Azadniv, M., Torres, A., Boscia, J., Speers, D.M., Frasier, L.M., Utell, M.J., Frampton, M.W., 2001. Neutrophils in lung inflammation: which reactive oxygen species are being measured? Inhal. Toxicol. 13, 485-495.

Borregaard, N., Cowland, J.B., 1997. Granules of the human neutrophilic polymorphonuclear leukocyte. Blood 89, 3503-3521.

Burkatovskaya, M., Tegos, G.P., Swietlik, E., Demidova, T.N.A.P.C., Hamblin, M.R., 2006. Use of chitosan bandage to prevent fatal infections developing from highly contaminated wounds in mice. Biomaterials 27, 4157-4164.

Chander, C.L., Moore, A.R., Lewis, G.M., Colville-Nash, P.R., Desa, F.M., Howat, D.W., Willoughby, D.A., 1989. Myofibroblasts in cotton-induced granulation tissue and the bovine adrenal capsule: morphological aspects. Int. J. Tissue React. 11, 161-163.

Etienne, O., Schneider, A., Taddei, C., Richert, L., Schaaf, P., Voegel, J.C., Egles, C., Picart, C., 2005. Degradability of polysaccharides multilayer films in the oral environment: an in vitro and in vivo study. Biomacromolecules 6 , 726-733.

Fadeel, B., Ahlin, A., Henter, J.I., Orrenius, S., Hampton, M.B., 1998. Involvement of caspases in neutrophil apoptosis: regulation by reactive oxygen species. Blood 92, 4808-4818.

Howling, G.I., Dettmar, P.W., Goddard, P.A., Hampson, F.C., Dornish, M., Wood, E.J., 2001. The effect of chitin and chitosan on the proliferation of human skin fibroblasts and keratinocytes in vitro. Biomaterials 22, 2959-2966.

Hunt, J.A., 2001. Inflammation. In: Buschow, K.H.J., Cahn, R.W., Flemings, M.C., Ilschner, B., Kramer, E.J., Mahajan, S. (Eds.), Encyclopedia of Materials: Science and Technology. Elsevier Science Ltd.

Ishihara, M., Ono, K., Sato, M., Nakanishi, K., Saito, Y., Yura, H., Matsui, T., Hattori, H., Fujita, M., Kikuchi, M., Kurita, A., 2001. Acceleration of wound contraction and healing with a photocrosslinkable chitosan hydrogel. Wound Repair Regen 9, 513-521.

Jackson, J.K., Springate, C.M., Hunter, W.L., Burt, H.M., 2000. Neutrophil activation by plasma opsonized polymeric microspheres: inhibitory effect of pluronic F127. Biomaterials 21, 1483-1491.
Khor, E., Lim, L.Y., 2003. Implantable applications of chitin and chitosan. Biomaterials 24, 2339-2349.

Lee, Y.-T., Don, M.-J., Liao, C.-H., Chiou, H.-W., Chen, C.-F., Ho, L.-K., 2005. Effects of phenolic acid esters and amides on stimulus-induced reactive oxygen species production in human neutrophils. Clin. Chim. Acta 352, $135-141$.

Li, Y., Zhu, H., Kuppusamy, P., Roubaud, V., Zweier, J.L., Trush, M.A., 1998. Validation of lucigenin (bis- $N$-methylacridinium) as a chemilumigenic probe for detecting superoxide anion radical production by enzymatic and cellular systems. J. Biol. Chem. 273, 2015-2023.

Liu, L., Elwing, H., Karlsson, A., Nimeri, G., Dahlgren, C., 1997. Surfacerelated triggering of the neutrophil respiratory burst. Characterization of the response induced by IgG adsorbed to hydrophilic and hydrophobic glass surfaces. Clin. Exp. Immunol. 109, 204-210.

Marques, A.P., Reis, R.L., Hunt, J.A., 2003. Evaluation of the potential of starchbased biodegradable polymers in the activation of human inflammatory cells. J. Mater. Sci. Mater. Med. 14, 167-173.

Marques, A.P., Reis, R.L., Hunt, J.A., 2004. Cytokine secretion from mononuclear cells cultured in vitro with starch-based polymers and poly-L-lactide. J. Biomed. Mater. Res. 71A, 419-429.

Marques, A.P., Reis, R.L., Hunt, J.A., 2005. An in vivo study of the host response to starch-based polymers and composites subcutaneously implanted in rats. Macromol. Biosci. 5, 775-785.

Marreco, P.R., Da Luz Moreira, P., Genari, S.C., Moraes, A.M., 2004. Effects of different sterilization methods on the morphology, mechanical properties, and cytotoxicity of chitosan membranes used as wound dressings. J. Biomed. Mater. Res. 71B, 268-277.

Martin, P., Leibovich, S.J., 2005. Inflammatory cells during wound repair: the good, the bad and the ugly. Trends Cell. Biol. 15, 599-607.

McPhail, L.C., Henson, P.M., Johnston Jr, R.B., 1981. Respiratory burst enzyme in human neutrophils. Evidence for multiple mechanisms of activation. J. Clin. Invest. 67, 710-716.

Melloni, E., Pontremoli, S., Michetti, M., Sacco, O., Sparatore, B., Horecker, B.L., 1986. The involvement of calpain in the activation of protein kinase $\mathrm{C}$ in neutrophils stimulated by phorbol myristic acid. J. Biol. Chem. 261, 4101-4105.

Mikos, A.G., Mcintire, L.V., Anderson, J.M., Babensee, J.E., 1998. Host response to tissue engineered devices. Adv. Drug Deliv. Rev. 33, 111-139.

Mutasa, H.C., 1989. Analysis of human neutrophil granule protein composition in chronic myeloid leukaemia by immuno-electron microscopy. Cell Tissue Res. 258, 111-117.

Nimeri, G., Ohman, L., Elwing, H., Wettero, J., Bengtsson, T., 2002. The influence of plasma proteins and platelets on oxygen radical production and F-actin distribution in neutrophils adhering to polymer surfaces. Biomaterials 23, 1785-1795.

Pedro, P.P.B.M., Peterbauer, A.J., Gabriel, A., Redl, C.H., Reis, R.L., 2005. Chitosan particles agglomerated scaffolds for cartilage and osteochondral tissue engineering approaches with adipose tissue derived stem cells. J. Mater. Sci. Mater. Med. 16, 1077-1085.

Reis, R.L., Mendes, S.C., Cunha, A.M., Bevis, M.J., 1997. Processing and in vitro degradation of starch/EVOH thermoplastic blends. Polym. Int. 43, 347.

Rice, W.G., Kinkade Jr, J.M., Parmley, R.T., 1986. High resolution of heterogeneity among human neutrophil granules: physical, biochemical, and ultrastructural properties of isolated fractions. Blood 68, 541-555.

Robinson, J.P., 1998. Oxygen and Nitrogen Reactive Metabolites and Phagocytic Cells. Wiley-Liss, Inc.

Salton, M.R., 1957. The properties of lysozyme and its action on microorganisms. Bacteriol. Rev. 21, 82-100.

Schwartz, B.R., Karsan, A., Bombeli, T., Harlan, J.M., 1999. A novel beta 1 integrin-dependent mechanism of leukocyte adherence to apoptotic cells. J. Immunol. 162, 4842-4848.

Segal, A.W., 2005. How neutrophils kill microbes. Annu. Rev. Immunol. 23 , 197-223.

Shi, C., Zhu, Y., Ran, X., Wang, M., Su, Y., Cheng, T., 2006. Therapeutic potential of chitosan and its derivatives in regenerative medicine. J. Surg. Res.

Silva, R.M., Elvira, C., Mano, J.F., San Roman, J., Reis, R.L., 2004. Influence of beta-radiation sterilisation in properties of new chitosan/soybean protein 
isolate membranes for guided bone regeneration. J. Mater. Sci. Mater. Med. $15,523-528$.

Silva, S.S., Goodfellow, B.J., Benesch, J., Rocha, J., Mano, J.F., Reis, R.L., 2007. Morphology and miscibility of chitosan/soy protein blended membranes. Carbohydrate Polym. 70, 25-31.

Silva, S.S., Oliveira, J.M., Luna, S.M., Benesch, J., Gomes, M.E., Mano, J.F., Reis, R.L., submitted for publication. Development of novel chitosan/soy protein based hybrid membranes prepared by means of an in situ crosslinking process.

Silva, S.S., Oliveira, J.M., Mano, J.F., Reis, R.L., 2006. Physicochemical characterization of novel chitosan-soy protein/TEOS porous hybrids for tissue engineering applications. Mater. Sci. Forum 514-516, 1000 1004.

Silva, S.S., Santos, M.I., Coutinho, O.P., Mano, J.F., Reis, R.L., 2005. Physical properties and biocompatibility of chitosan/soy blended membranes. J. Mater. Sci. Mater. Med. 16, 575-579.
Singla, A.K., Chawla, M., 2001. Chitosan: some pharmaceutical and biological aspects—an update. J. Pharm. Pharmacol. 53, 1047-1067.

Stevens, A., Lowe, J.S., Young, B., 2002. Wheater's Basic Histopathology: A Colour Atlas and Text. Edinburgh, Churchill Livingstone.

Tuo, J., Loft, S., Poulsen, H.E., 1999. Enhanced benzene-induced DNA damage in PMA-stimulated cells in vitro and in LPS-treated animals. Free Radic. Biol. Med. 26, 801-808.

Tuzlakoglu, K., Alves, C.M., Mano, J.F., Reis, R.L., 2004. Production and characterization of chitosan fibers and 3-D fiber mesh scaffolds for tissue engineering applications. Macromol. Biosci. 4, 811-819.

Wedmore, I., Mcmanus, J.G., Pusateri, A.E., Holcomb, J.B., 2006. A special report on the chitosan-based hemostatic dressing: experience in current combat operations. J. Trauma 60, 655-658.

Williams, D.F., 2001. Biocompatibility principles. In: Buschow, K.H.J., Cahn, R.W., Flemings, M.C., Ilschner, B., Kramer, E.J., Mahajan, S. (Eds.), Encyclopedia of Materials: Science and Technology. Elsevier Science Ltd. 